BNL-112005-2016-IR- R1

\title{
A Reload and Startup Plan for Conversion of the NIST Research Reactor
}

\author{
D. J. Diamond, A. Varuttamaseni
}

September 2017

Nuclear Science \& Technology Department

Brookhaven National Laboratory

\section{U.S. Department of Energy National Nuclear Security Administration National Institute of Standards \& Technology}




\section{DISCLAIMER}

This report was prepared as an account of work sponsored by an agency of the United States Government. Neither the United States Government nor any agency thereof, nor any of their employees, nor any of their contractors, subcontractors, or their employees, makes any warranty, express or implied, or assumes any legal liability or responsibility for the accuracy, completeness, or any third party's use or the results of such use of any information, apparatus, product, or process disclosed, or represents that its use would not infringe privately owned rights. Reference herein to any specific commercial product, process, or service by trade name, trademark, manufacturer, or otherwise, does not necessarily constitute or imply its endorsement, recommendation, or favoring by the United States Government or any agency thereof or its contractors or subcontractors. The views and opinions of authors expressed herein do not necessarily state or reflect those of the United States Government or any agency thereof. 


\section{A RELOAD AND STARTUP PLAN FOR CONVERSION OF THE NIST RESEARCH REACTOR}

Manuscript Completed

September 14, 2017

Prepared by

D.J. Diamond and A. Varuttamaseni

Nuclear Science \& Technology Department

Brookhaven National Laboratory

Upton, NY 11973

Prepared for:

National Nuclear Security Administration

National Institute of Standards and Technology 


\begin{abstract}
The National Institute of Standards and Technology operates a 20 MW research reactor for neutron-based research. The heavy-water moderated and cooled reactor is fueled with highenriched uranium (HEU) but a program to convert the reactor to low-enriched uranium (LEU) fuel is underway. Among other requirements, a reload and startup test plan must be submitted to the U.S. Nuclear Regulatory Commission (NRC) for their approval. The NRC provides guidance for what should be in the plan to ensure that the licensee has sufficient information to operate the reactor safely. Hence, several reload plans and a startup test plan have been generated.

Although a final reload plan has yet to be determined, one approach was analyzed in detail to better understand how a reload plan might impact operations and safety. This plan specifies the fuel management whereby initially only two LEU fuel elements are in the core for eight fuel cycles. This Phase-1 transition is repeated until a point when the optimum approach is to place four fresh LEU elements into the reactor each cycle. This final Phase- 2 transition is repeated and after eight cycles the reactor is completely fueled with LEU. By only adding two LEU fuel elements initially, the plan allows for the consumption of HEU fuel elements that are expected to be in storage at the time of conversion and provides additional assurance that the production LEU fuel can be operated safely under actual operating conditions.
\end{abstract}

Because the reload is to take place over many fuel cycles, startup tests would be done at different stages of the conversion. The tests, to be compared with calculations to show that the reactor will operate as planned, are the measurement of critical shim arm position and shim arm and regulating rod reactivity worths. An acceptance criterion for each test is specified based on technical specifications that relate to safe operation. Additional tests are being considered that have less safety significance but may be of interest to bolster the validation of analysis tools. 


\section{TABLE OF CONTENTS}

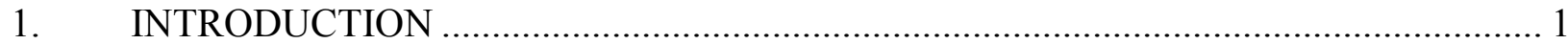

1.1 Objectives of the Reload and Startup Plan................................................................ 1

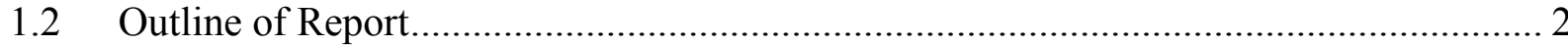

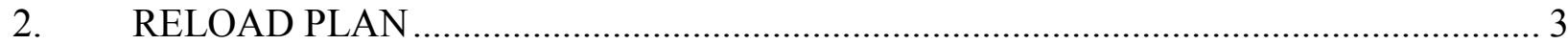

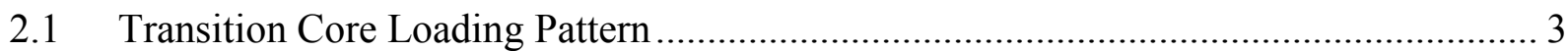

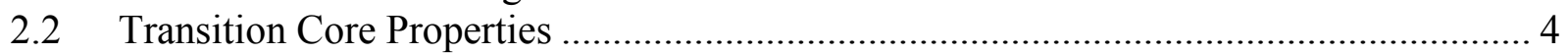

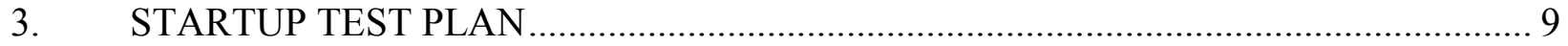

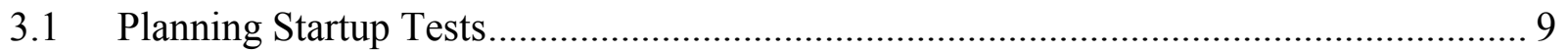

3.2 Critical Shim Arm Position ................................................................................ 10

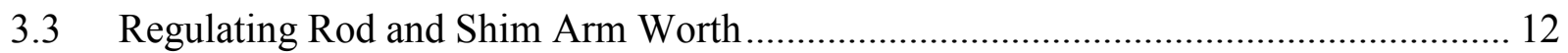

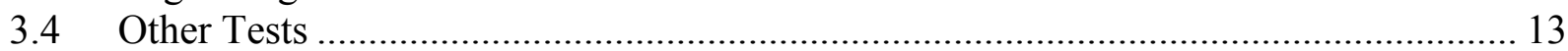

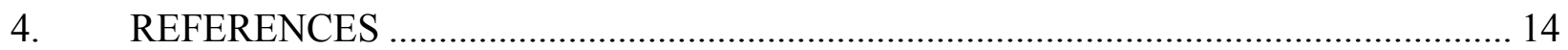

\section{ACKNOWLEDGMENTS}

This work was supported by the National Nuclear Security Administration and the NIST Center for Neutron Research (NCNR). The authors appreciate the information obtained from, and the review by, Thomas Newton, Robert Williams, Paul Brand, and Bryan Eyers at the NCNR. The authors also appreciate the support provided by Erik Wilson and Thad Heltemes at Argonne National Laboratory. 


\section{INTRODUCTION}

\subsection{Objectives of the Reload and Startup Test Plan}

The NIST (National Institute of Standards and Technology) research reactor (aka NBSR) is a heavy water moderated and cooled reactor operating at $20 \mathrm{MW}$. It provides users with thermal and cold neutron beams to carry out diverse world-class research. It is fueled with high-enriched uranium (HEU) fuel elements but a program is underway to convert the reactor to low-enriched uranium (LEU) fuel. To accomplish this, the fuel meat within each fuel plate will change from $\mathrm{U}_{3} \mathrm{O}_{8}$ (with fully enriched uranium) in an aluminum powder dispersion to U10Mo metal foil (with $19.75 \%$ enriched uranium). The Al cladding material and fuel plate external geometry will remain the same.

The U.S. Nuclear Regulatory Commission (NRC) has to approve the conversion proposal and provides guidance as to what should be in the proposal. In particular, Chapter 18 of NUREG1537 (NRC, 1996) provides the format and content for the conversion Safety Analysis Report (SAR) (in Part 1) and the standard review plan and acceptance criteria for the conversion SAR (in Part 2). Section 12.6 of the conversion SAR is to discuss the "Reactor Reload and Startup Plan" which is "to ensure that the licensee has sufficient information to operate the reactor safely."

According to the NRC guidance, the reload and startup plan (RSUP) "should provide for testing any newly installed equipment; a proposed fuel loading procedure and schedule; radiation surveys; a systematic set of subcritical measurements in the approach to critical with the new fuel; experiments and measurements that compare predicted and calculated reactor parameters; and verification of compliance with license conditions, including technical specifications, of the LEU-fueled reactor." How the NRC guidance is utilized for the NBSR RSUP is explained in this report. The RSUP is a supplement to the fuel qualification that will have preceded loading of the first LEU fuel element. This includes the irradiations of prototypic fuel plates that are planned at the Advanced Test Reactor at the Idaho National Laboratory [e.g., see

(Wolstenhulme, 2012)] and the hydraulic tests planned at Oregon State University (Marcum, 2013).

Although an otherwise complete preliminary SAR (Diamond, 2014) has been submitted to the $\mathrm{NRC}$, it was premature at the time of submittal to discuss both the way in which the reactor would be loaded with LEU fuel and what tests would be done to ensure that the reactor would operate as planned. Hence, that preliminary SAR only considered the eventual equilibrium LEU core with fuel elements as defined in (Hanson, 2011).

The NRC-suggested components of the conversion startup plan form the basic objectives of the NBSR plan discussed herein. The NRC guidance is blended with the operational needs and experience at the NBSR. This approach is also consistent with the guidelines set forth by the International Atomic Energy Agency in Appendix L of IAEA-TECDOC-643 (IAEA, 1992), which benefitted from the earlier work that had been done for NUREG-1537. 


\subsection{Outline of Report}

A possible approach to reloading the reactor with LEU fuel elements is discussed in Section 2. That plan is for a reload that will not take place at one time but will involve loading different amounts of LEU fuel elements at different times. The recommendation for tests then must be a function of the particular reloading taking place. The tests that would constitute the startup plan are provided in Section 3. The objective of these tests is to assure that the LEU fueled core matches the core that was expected (i.e., previously calculated) and for which the safety analysis was carried out. This requires each test to have an acceptance criterion. Section 4 contains references. 


\section{RELOAD PLAN}

\subsection{Transition Core Loading Pattern}

It is not possible to simply replace a core containing HEU fuel in an equilibrium burnup state with a core consisting of fresh LEU fuel elements (FEs). This would lead to a core having an excess reactivity and a shutdown margin that violate the reactor's Technical Specifications (NIST, 2010). Hence, it is necessary to have a reload plan that only reloads a fraction of the core with fresh LEU fuel elements at any given time, or uses a core filled with LEU elements with different enrichments to simulate an equilibrium core. The latter option complicates the fuel fabrication process and since the former approach leads to other benefits, to be discussed below, this is the approach to be taken.

A reload plan must satisfy safety criteria and should minimize operational problems. The latter means that it would be advantageous to make use of the current fuel management scheme, provide sufficient reactivity in the core for the desired cycle length, and maximize the flux at the core periphery for use in the experimental program. The current fuel management scheme removes four fuel elements every 38.5-day cycle; the remaining fuel is reshuffled, and four fresh elements are added. There are a total of 30 FEs, so two of the fresh elements stay in the core for eight cycles and two for seven cycles. The placement of fuel elements in the core is shown on the grid in Figure 1. The fuel elements are placed symmetrically in the east (E) and west (W) sides of the core and each is designated N-C where $\mathrm{N}$ is either "7" or " 8 ", depending on whether it will be in for seven or eight cycles, and $\mathrm{C}$ is the cycle it is experiencing. Hence, in grid location D1 the fuel element (8-1W) that will experience eight cycles is in its first cycle on the west side of the core. Also represented on the grid in Figure 1 are the locations of the major cold source (CS), the regulating rod (RR) and irradiation thimbles $(<>)$.

\begin{tabular}{|l|c|c|c|c|c|c|c|c|c|c|c|c|c|}
\hline & A & B & C & D & E & F & G & H & I & J & K & L & M \\
\hline 1 & & & & & CS & & & & & & & & \\
\hline 2 & & & $8-3 W$ & & $7-5 W$ & & $<$ & & $7-5 E$ & & $8-3 E$ & & \\
\hline 3 & & $7-3 W$ & & $<$ & & $8-7 W$ & & $8-7 E$ & & $<$ & & $7-3 E$ & \\
\hline 4 & $7-1 W$ & & $8-6 W$ & & $7-7 W$ & & $<$ & & $7-7 E$ & & $8-6 E$ & & $7-1 E$ \\
\hline 5 & & $8-4 W$ & & $<$ & & $8-8 W$ & & $8-8 E$ & & $<$ & & $8-4 E$ & \\
\hline 6 & & & $7-4 W$ & & $7-6 W$ & & $R R$ & & $7-6 E$ & & $7-4 E$ & & \\
\hline 7 & & & & $8-2 W$ & & $8-5 W$ & & $8-5 E$ & & $8-2 E$ & & & \\
\hline
\end{tabular}

Figure 1. NBSR Core Layout 
If the four fresh elements are LEU, this would eliminate all HEU fuel and lead to a $100 \% \mathrm{LEU}$ core in eight cycles. However, instead of that approach, a two-phase process is being considered. The Phase-1 transition (Hanson, 2012) is motivated by the assumption that there will still be a large inventory of HEU fuel elements available at the time that the production LEU fuel elements become available. Hence, the plan is to initially load two LEU fuel elements for eight cycles and two HEU fuel elements for seven cycles. The following seven cycles would each load four HEU fuel elements and then after the two LEU fuel elements are removed after the eighth cycle, two fresh LEU elements would be added in the next cycle. This process would proceed until sufficient HEU fuel elements have been utilized and at that point only four LEU elements would be loaded every cycle. This latter fuel management is considered the Phase-2 transition.

The Phase- 1 and Phase- 2 transitions are shown in Figure 2 and Appendix A has the specific fuel loading for each location as a function of cycle. The criteria that will be used to decide whether to continue Phase-1 or move to Phase-2 ("Phase-1 transition to continue?" on Figure 2) are twofold. The first criterion is the number of HEU fuel elements remaining. For example if there is a two-year supply of HEU FEs available when the conversion first takes place, then there will be approximately 60 available and if 30 are utilized every eight cycles (along with the two LEU elements), then Phase-1 can continue for 16 fuel cycles. This is consistent with the fact that leaving viable HEU elements unused is counter to the criterion that conversion should not pose an unreasonable cost burden on the facility.

The second criterion relates to the other motivation for using the Phase-1 approach. Although prototypic fuel will have been irradiated as part of the fuel qualification program, none of the proposed tests use an actual production NBSR fuel element. Hence, the Phase-1 approach conservatively prepares for uncertainties in supply and performance of the new fuel. In the unlikely event that there is a problem during Phase-1, which necessitates the removal of the LEU fuel, it would not be too difficult to get the reactor operational again with only HEU fuel. Hence, a second criterion for moving to Phase- 2 is the absence of any data or information that indicates LEU fuel is not performing as expected.

\subsection{Transition Core Properties}

An analysis of two Phase-1 cycles (a total of 16 fuel cycles) was carried out and documented in (Hanson, 2012). It shows that there are no major neutronic or power distribution issues if two LEU fuel elements are inserted into the NBSR core to act as lead acceptance elements.

However, there will be a decrease in the excess reactivity after loading the LEU fuel elements so that the first cycle will not be able to operate for 38.5 days; it is expected to operate for only 37.4 days. All subsequent cycles are expected to be able to last no less than 38 days and most at least 38.5 days. The calculations of the excess reactivity and shutdown margin show compliance with Technical Specification 3.1.2, Reactivity Limitations. There will be a small decrease in the neutron beam performance, the magnitude of which will change as the LEU elements are moved through the core. Calculations of shim arm critical position at startup; neutron lifetime and delayed neutron fraction; and moderator temperature coefficient and reactivity; showed that these parameters will not change significantly when the LEU is added to the core during the Phase-1 program (Hanson, 2012). 


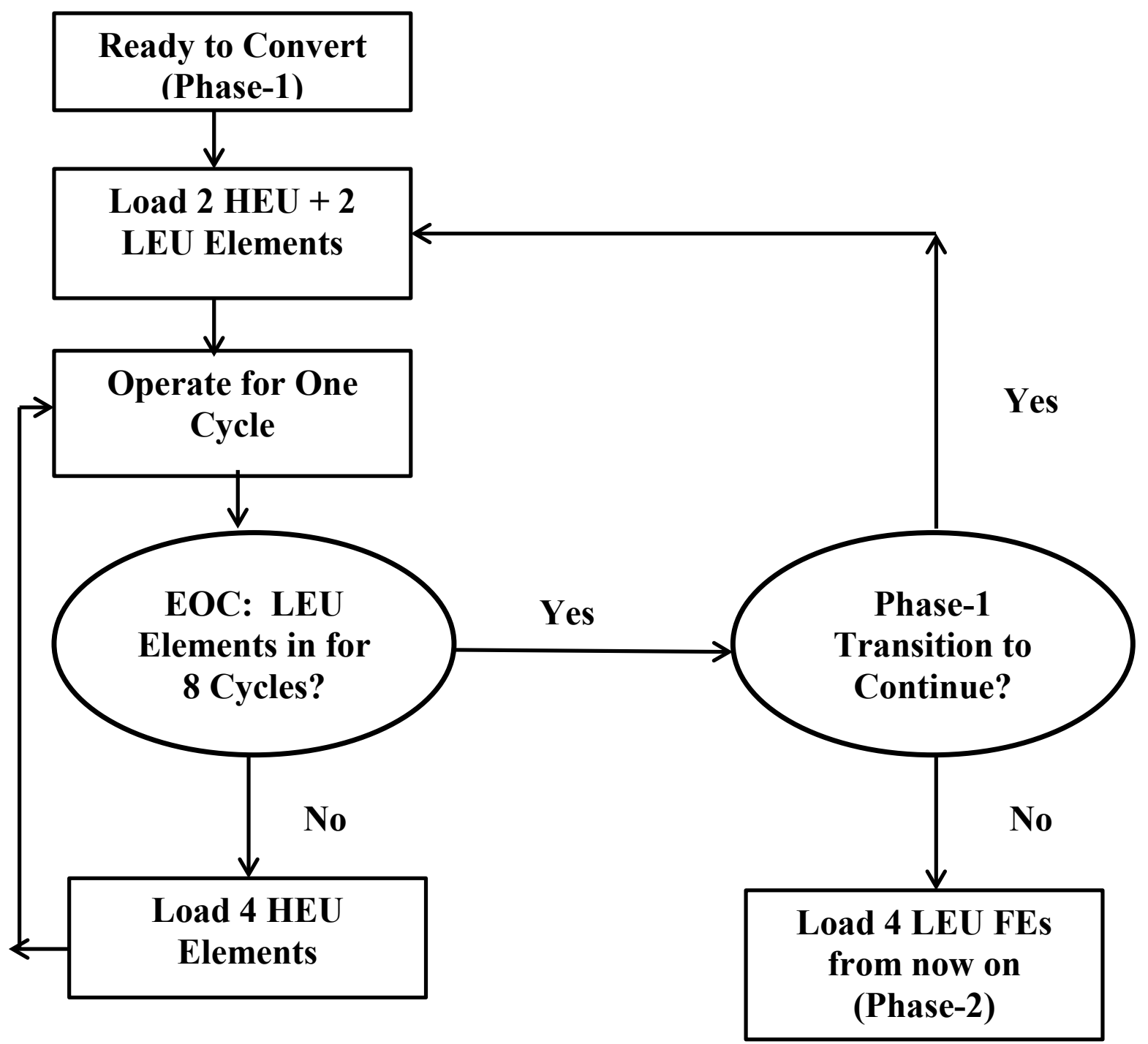

Figure 2. Flow Diagram for Transition from HEU to LEU Fuel

The power distribution will change as the LEU elements move through the core. For the equilibrium cores, the highest half-element relative power is 1.28 with HEU fuel and 1.35 with LEU fuel. This occurs at startup, the time during a fuel cycle with the highest power peaking (Diamond, 2014). The calculations of the 16 Phase-1 transition cores (Hanson, 2012) show that the highest half-element power increases to 1.39 at startup, an insignificant amount as will be shown below.

A similar analysis was carried out for the Phase-2 transition with the insertion of four LEU fuel elements every cycle until cycle eight (and beyond) when the core is completely loaded with LEU (Hanson, 2013a). However, as with Phase-1, there is insufficient excess reactivity during the transition to assure 38.5-day cycles. A solution is to have the first transition cycle with a reduced length ( 22 days will work) leaving enough excess reactivity so that the remaining cycles 
can be the standard 38.5-day length. This approach would result in a transition that would not be in violation of Technical Specifications on excess reactivity and shutdown margin.

The analysis done in (Hanson, 2013) shows that neutronic properties are either not changed significantly or are still considered to be within the required safety envelope. This includes shim arm worth, prompt neutron lifetime, delayed neutron parameters, and moderator temperature and void reactivity coefficient.

The power distribution will change through the Phase- 2 transition as the power with HEU fuel is optimized to provide neutrons to peripheral beams whereas the increase in ${ }^{238} \mathrm{U}$ in the LEU fuel increases parasitic absorption of higher energy neutrons and causes the flux to peak towards the center of the core. Tables I and II (Hanson, 2013a) give the hottest spots, stripes and halfelement powers at startup (SU) and end-of-cycle (EOC) during the eight transition cycles (TCs) and for the equilibrium HEU and LEU cores. The tables also show the particular FE and whether the peak value is in the upper (U) half of the fuel element or the lower (L) half.

Table I Hottest Spots, Stripes and Half-Element Powers at SU (Phase 2)

\begin{tabular}{|c|c|c|c|c|c|c|c|c|c|}
\hline & \multicolumn{3}{|c|}{ Hottest Spot } & \multicolumn{3}{|c|}{ Hottest Stripe } & \multicolumn{3}{|c|}{ Hottest Half FE } \\
\hline & Rel. Value & $\mathrm{FE}$ & Fuel & Rel. Value & $\mathrm{FE}$ & Fuel & Rel. Value & $\mathrm{FE}$ & Fuel \\
\hline HEU & 2.48 & $7-2 \mathrm{E} / \mathrm{L}$ & HEU & 1.81 & $8-3 \mathrm{E} / \mathrm{L}$ & HEU & 1.28 & $7-5 \mathrm{E} / \mathrm{L}$ & $\mathrm{HEU}$ \\
\hline TC1 & 2.42 & $7-2 \mathrm{E} / \mathrm{L}$ & HEU & 1.78 & $7-1 \mathrm{~W} / \mathrm{L}$ & LEU & 1.26 & $8-7 \mathrm{~W} / \mathrm{L}$ & $\mathrm{HEU}$ \\
\hline TC2 & 2.53 & $7-2 \mathrm{E} / \mathrm{L}$ & LEU & 1.78 & $8-3 \mathrm{E} / \mathrm{L}$ & HEU & 1.34 & $8-7 \mathrm{E} / \mathrm{L}$ & HEU \\
\hline TC3 & 2.55 & $7-3 \mathrm{E} / \mathrm{L}$ & LEU & 1.90 & $7-3 \mathrm{~W} / \mathrm{L}$ & LEU & 1.32 & $8-7 \mathrm{~W} / \mathrm{L}$ & $\mathrm{HEU}$ \\
\hline TC4 & 2.59 & $8-4 \mathrm{~W} / \mathrm{L}$ & LEU & 1.92 & $8-4 \mathrm{~W} / \mathrm{L}$ & LEU & 1.32 & $8-7 \mathrm{~W} / \mathrm{L}$ & $\mathrm{HEU}$ \\
\hline TC5 & 2.70 & $7-5 \mathrm{~W} / \mathrm{L}$ & LEU & 2.02 & $7-5 \mathrm{~W} / \mathrm{L}$ & LEU & 1.37 & $7-5 \mathrm{~W} / \mathrm{L}$ & LEU \\
\hline TC6 & 2.60 & $7-5 \mathrm{~W} / \mathrm{L}$ & LEU & 1.96 & $7-5 \mathrm{~W} / \mathrm{L}$ & LEU & 1.33 & $8-6 \mathrm{~W} / \mathrm{L}$ & LEU \\
\hline TC7 & 2.63 & $7-5 \mathrm{~W} / \mathrm{L}$ & LEU & 1.92 & $7-7 \mathrm{~W} / \mathrm{L}$ & HEU & 1.44 & $7-7 \mathrm{~W} / \mathrm{L}$ & LEU \\
\hline TC8 & 2.53 & $7-5 \mathrm{~W} / \mathrm{L}$ & LEU & 1.91 & $7-5 \mathrm{~W} / \mathrm{L}$ & LEU & 1.40 & $8-7 \mathrm{~W} / \mathrm{L}$ & LEU \\
\hline LEU & 2.43 & $8-3 \mathrm{E} / \mathrm{L}$ & LEU & 1.78 & $8-3 \mathrm{E} / \mathrm{L}$ & LEU & 1.35 & $8-7 \mathrm{~W} / \mathrm{L}$ & LEU \\
\hline
\end{tabular}

Table II Hottest Spots, Stripes and Half-Element Powers at EOC (Phase 2)

\begin{tabular}{|c|c|c|c|c|c|c|c|c|c|}
\hline & \multicolumn{3}{|c|}{ Hottest Spot } & \multicolumn{3}{c|}{ Hottest Stripe } & \multicolumn{3}{c|}{ Hottest Half FE } \\
\hline & Rel. Value & FE & Fuel & Rel. Value & FE & Fuel & Rel. Value & FE & Fuel \\
\hline HEU & 2.19 & $\begin{array}{c}7- \\
1 \mathrm{~W} / \mathrm{U}\end{array}$ & HEU & 1.66 & $7-2 \mathrm{E} / \mathrm{U}$ & $\mathrm{HEU}$ & 1.18 & $7-2 \mathrm{E} / \mathrm{U}$ & $\mathrm{HEU}$ \\
& & & & & & & \\
\hline TC1 & 2.26 & $7-1 \mathrm{E} / \mathrm{U}$ & LEU & 1.64 & $7-2 \mathrm{E} / \mathrm{U}$ & $\mathrm{HEU}$ & 1.14 & $7-2 \mathrm{E} / \mathrm{U}$ & $\mathrm{HEU}$ \\
\hline TC2 & 2.27 & $7-1 \mathrm{E} / \mathrm{U}$ & LEU & 1.73 & $7-2 \mathrm{E} / \mathrm{U}$ & LEU & 1.15 & $7-2 \mathrm{E} / \mathrm{U}$ & $\mathrm{LEU}$ \\
\hline TC3 & 2.43 & $7-3 \mathrm{~W} / \mathrm{L}$ & LEU & 1.73 & $7-3 \mathrm{~W} / \mathrm{L}$ & LEU & 1.14 & $7-3 \mathrm{E} / \mathrm{U}$ & $\mathrm{LEU}$ \\
\hline TC4 & 2.42 & $7-3 \mathrm{~W} / \mathrm{L}$ & LEU & 1.67 & $7-3 \mathrm{~W} / \mathrm{L}$ & LEU & 1.12 & $7-5 \mathrm{E} / \mathrm{U}$ & $\mathrm{HEU}$ \\
\hline TC5 & 2.38 & $7-3 \mathrm{~W} / \mathrm{L}$ & LEU & 1.66 & $7-3 \mathrm{~W} / \mathrm{L}$ & LEU & 1.16 & $7-5 \mathrm{E} / \mathrm{U}$ & $\mathrm{LEU}$ \\
\hline TC6 & 2.29 & $7-3 \mathrm{~W} / \mathrm{L}$ & LEU & 1.64 & $7-3 \mathrm{~W} / \mathrm{L}$ & LEU & 1.12 & $7-5 \mathrm{~W} / \mathrm{U}$ & $\mathrm{LEU}$ \\
\hline TC7 & 2.28 & $7-3 \mathrm{~W} / \mathrm{L}$ & LEU & 1.63 & $7-3 \mathrm{~W} / \mathrm{L}$ & LEU & 1.16 & $7-7 \mathrm{~W} / \mathrm{L}$ & LEU \\
\hline TC8 & 2.25 & $8-3 \mathrm{~W} / \mathrm{L}$ & LEU & 1.61 & $7-3 \mathrm{~W} / \mathrm{L}$ & LEU & 1.12 & $8-7 \mathrm{~W} / \mathrm{L}$ & LEU \\
\hline LEU & 2.21 & $7-3 \mathrm{E} / \mathrm{U}$ & LEU & 1.65 & $7-2 \mathrm{E} / \mathrm{U}$ & LEU & 1.15 & $8-7 \mathrm{E} / \mathrm{U}$ & $\mathrm{LEU}$ \\
\hline
\end{tabular}


SU is when the peak steady state power is present but EOC is when the transient minimum thermal margin is found. Based on the analysis done for reactivity insertion and loss of flow events (Diamond, 2014) the minimum thermal margin occurs during the postulated uncontrolled removal of shim arms starting at low power (the "startup accident") and refers to minimum critical heat flux ratio (MCHFR) and minimum onset of flow instability ratio (MOFIR). As one can see from Table II, the maximum change in the hottest spot at EOC, relative to an equilibrium core, is $(2.43 / 2.21) 1.10$, that is an increase of $10 \%$. The maximum change in the hottest stripe is less than $5 \%$.

In order to see what change in power peaking might lead to an unacceptable decrease in thermal margin, a series of RELAP5 calculations was completed for the startup accident and the statistical analysis used to calculate thermal margin (NIST, 2010) was invoked. The RELAP5 analysis utilized the model generated for the equilibrium LEU core (Diamond, 2014) but with arbitrary scaling of the power in the limiting coolant channels with either the hottest stripe or the hottest spot. The results for MCHFR are given in Table III; results for MOFIR show even larger margins.

Table III MCHFR with Arbitrary Scaling Factors

\begin{tabular}{|c|c|c|}
\hline Scaling Factor & $\begin{array}{c}\text { MCHFR with Hot } \\
\text { Spot Scaled }\end{array}$ & $\begin{array}{c}\text { MCHFR with Hot } \\
\text { Stripe Scaled }\end{array}$ \\
\hline 1.00 & 2.07 & 2.07 \\
\hline 1.05 & 1.96 & 1.95 \\
\hline 1.10 & 1.86 & 1.74 \\
\hline 1.15 & 1.77 & 1.66 \\
\hline 1.20 & 1.69 & 1.58 \\
\hline 1.25 & 1.62 & \\
\hline
\end{tabular}

The MCHFR results show that even with the extreme assumption of a $25 \%$ increase in power peaking, the MCHFR does not fall below 1.58. This corresponds to a probability of not reaching critical heat flux of 99\%. The statistical hot channel analysis (Cuadra, 2014), as summarized in Figure 3, shows the probability of not exceeding CHF for a particular MCHFR. When the MCHFR is above 1.4 there is still a $95 \%$ probability that CHF will not be reached.

In summary, these analyses show that the assumed transition cores will be able to be operated normally with the exception of having a shorter first cycle to make up for a shortage of reactivity. They will also be able to operate safely as evidenced by considering changes to parameters like shutdown margin and thermal margin. The hot spots in Table I are conservative 
estimates because they all occur in partially burned elements in which these spots experienced more depletion of U-235 than the average fuel material in that half element (Brown, 2013).

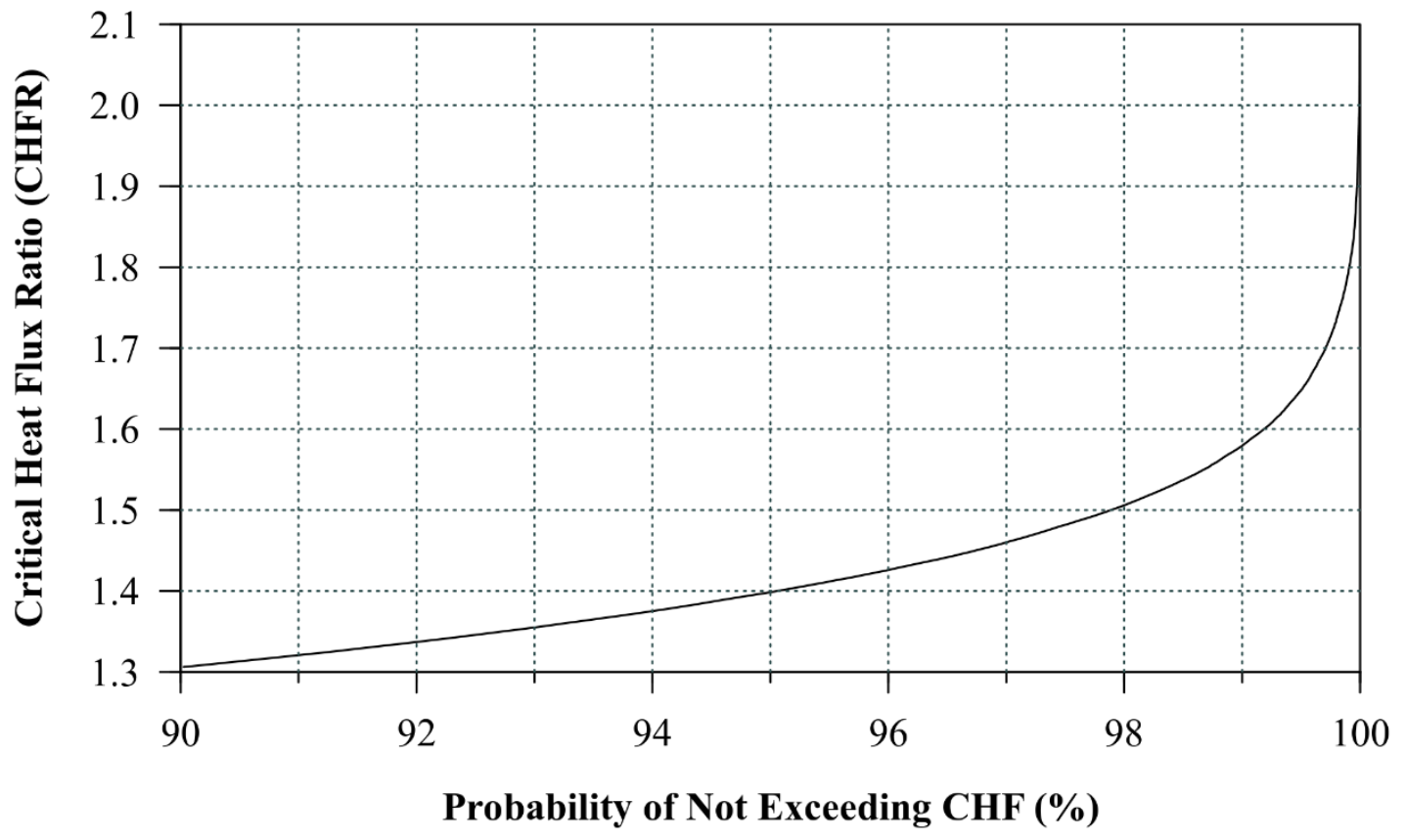

Figure 3. Cumulative Distribution Function for Critical Heat Flux Ratio 


\section{STARTUP TEST PLAN}

\subsection{Planning Startup Tests}

The NRC guidance for the startup plan [Chapter 18 in Part 1 of $(\mathrm{NRC}, 1996)]$ states that the startup plan should contain:

- "a well-planned systematic set of subcritical multiplication measurements or an inverse multiplication approach to critical measurement during new fuel loading, and confirmation that analysis subcritical multiplication or critical fuel loading are within preestablished acceptable limits

- an experimental measurement plan to determine the important operational reactor physics parameters (such as control rod worth, excess reactivity, reactor thermal power, coefficients of reactivity, and power peaking factors) and thermal-hydraulic parameters (such as fuel, cladding, and coolant temperatures, reactor coolant system flow rates, and pressure drops, if appropriate), comparisons with predictions and acceptance criteria ...

- measurements of magnitudes of area radiation fields and radioactive effluents, and comparisons with the same parameters for operation of the HEU-fueled reactor and preestablished acceptance criteria ..."

For the NBSR, extensive tests are not needed if the proposed reload plan given in Section 2 is applied. That plan shows that the conversion will be gradual, with only either two or four fresh LEU fuel elements (FEs) placed in the core at the beginning of each cycle during the transition. Hence, each reload fuel cycle is only a perturbation of a well-known core. Subcritical multiplication is normally monitored when the reactor is loaded from a fully unloaded condition-something that might be necessitated by a long shutdown. However, the assumption herein is that the loading of LEU fuel will take place as part of a normal refueling. There are no changes to the thermal-hydraulic design of the core and the impact of a heavier element (the weight of the fuel element increases from $11.4 \mathrm{~kg}$ to $12.7 \mathrm{~kg}$ ) on the bypass flow is being determined by the aforementioned hydraulic tests at Oregon State University.

The objective of the formal startup plan that must be submitted to the NRC is the verification of compliance with license conditions. There are only a few technical specifications (NIST, 2010) ("Tech Specs"; specifically, "limiting conditions for operation") that need reconfirmation as a result of the change in fuel. The Tech Spec on reactivity limitations has a maximum allowable excess reactivity and minimum shutdown margin that must be confirmed. The Tech Spec on reactor control and safety systems has a maximum reactivity insertion rate for the shim arms that also must be confirmed.

The excess reactivity is checked by measuring the critical shim angle and then the differential total shim arm worth (which in turn needs the measurement of the regulating rod worth). The shutdown margin is determined by knowing the excess reactivity and measuring the individual shim arm worths. The maximum reactivity insertion rate is known by measuring the maximum differential worth of the shim arms. Each of these measurements is currently part of the normal 
operating procedures for the NBSR [e.g., (NIST, 2014)]. None of these measurements are expected to show a significant change when the LEU fuel is loaded. For example, the calculated excess reactivity for the current core at startup is $6.7 \% \Delta \mathrm{k} / \mathrm{k}$ and the corresponding number for the equilibrium (totally converted) LEU core is $6.3 \% \Delta \mathrm{k} / \mathrm{k}$. The difference, $0.4 \% \Delta \mathrm{k} / \mathrm{k}$, represents a small change taking place over several cycles.

As described in Section 2, the reload with LEU fuel takes place over a long period of time and includes many different core configurations, however, the formal startup tests need only be done at selected times during this process. One reason for this is that the critical shim arm position is measured at every startup as part of normal operations, and would alert to any reactivity anomalies and the regulating rod and shim arm worths are measured at least once a year--again independent of the fact that LEU is being added to the core.

The recommended times for the formal startup tests are:

- The start of the Phase-1 cycles, i.e., when the first two LEU fuel elements are introduced into the core.

- The start of the final transition cycles, i.e., when the first loading of four LEU fuel elements takes place.

- The start of two cycles later; i.e., when there are 12 LEU fuel elements in the core and the core might be considered significantly fueled with LEU.

- The start of the eighth cycle loading four LEU fuel elements; i.e., when all 30 fuel elements are LEU elements.

Since the NRC requests (NRC, 1996) that a startup report be submitted within six months of startup, it is proposed that two reports be written: one within six months of the initial LEU loading and one after completion of all tests in the plan--possibly several years later, depending on the number of Phase- 1 cycles. The tests and the rationale for when they are performed are explained in more detail in the following sections.

\subsection{Critical Shim Arm Position}

The critical shim arm position is currently recorded at the startup of every fuel cycle when the reactor is at $1 \mathrm{MW}$. It is a check of the reactivity of the core and hence, it is an obvious part of the startup plan for each time there is significant change to the core loading.

An estimated critical position (ECP) is calculated (Eyers, 2015) every cycle as part of normal operations. It is based on how long the reactor was shut down before startup and the length of previous cycles; indications of the current excess reactivity. It also corrects for regulating rod position, coolant temperature and shim arm burnup. The acceptance criterion currently used for this measurement is $\pm 1.0^{\circ}$ (NIST, 2015), i.e., if the measurement is more than one degree away from the ECP the startup test is not acceptable and the reason for the discrepancy must be determined. The acceptance criterion is based on a comparison of the estimated and measured critical positions for many past cycles which showed that the difference was almost always within that band. 
Data from three different shim arm position histories during the period 1995-2008 are shown on Figure 4. Each history corresponds to a different set of shim arms. The measured shim arm angles are at startup (before xenon buildup) and depend on the regulating rod position, the coolant temperature, the length of the previous cycle and, as shown on the graph, the number of cycles that the shim arms have been in the reactor (cycle number 1 corresponds to new shim arms). Also on the graph are calculations (connected by straight lines) for an idealized initial state but taking into account the impact of shim arm burnup (Hanson, 2013b). The calculations are based on the Monte Carlo model used to obtain the neutronics information for the SAR. The data points before the burnup of the shim arms becomes important are within $\sim \pm 0.5^{\circ}$ and the calculation is $\sim 0.5^{\circ}$ below the average of the data.

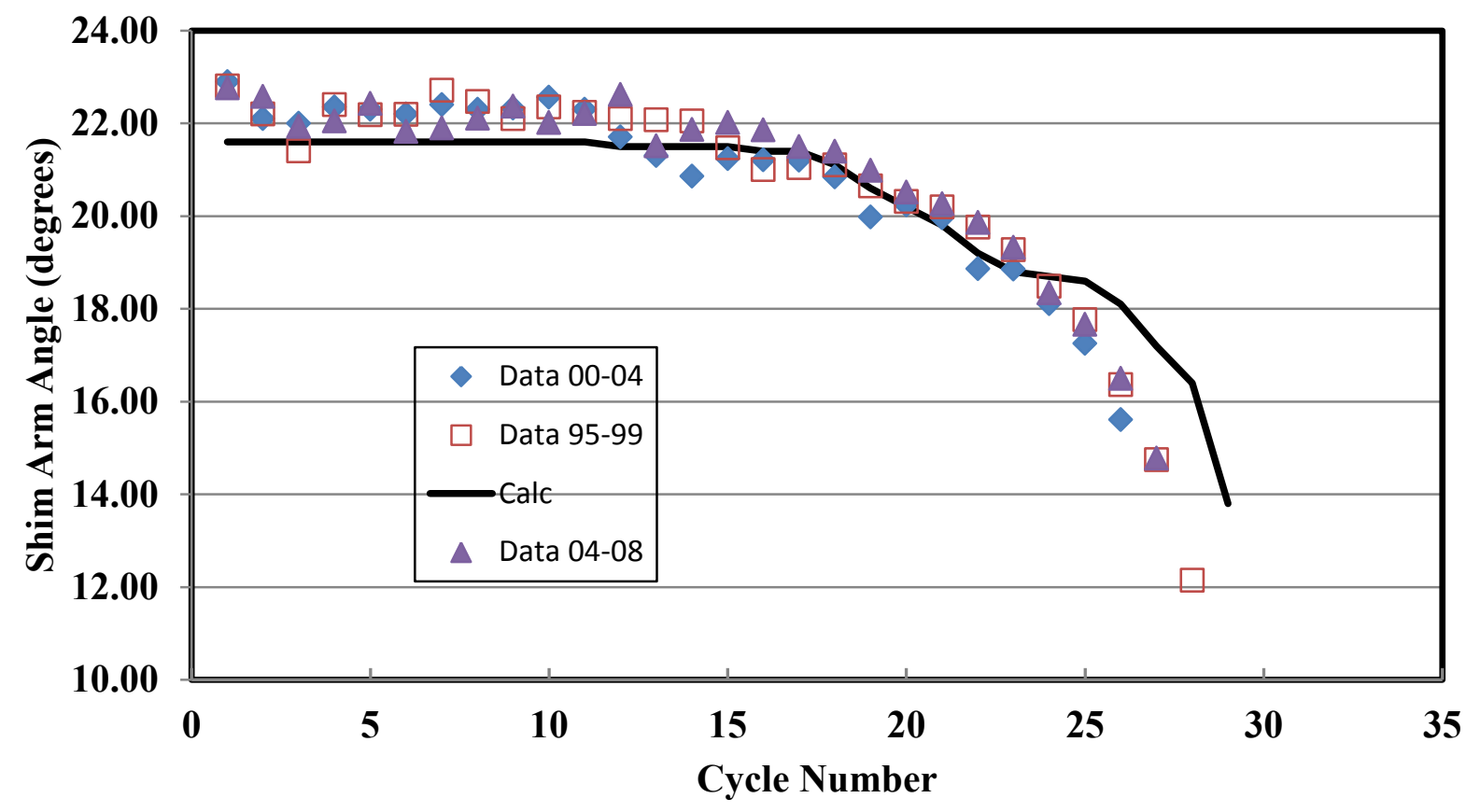

Figure 4. Critical Shim Arm Angle at Startup

When the first two LEU fuel elements are placed in the core, the excess reactivity is calculated to be reduced by $0.15 \% \Delta \rho$ (Hanson, 2012). It is not surprising that this is a small perturbation as the LEU fuel is supposed to support the same operations as did the HEU fuel. The corresponding change in critical shim arm angle is obtained by noting that the calculation of shim arm differential worth with either HEU or LEU fuel is on the order of $0.6-0.7 \% \Delta \rho /$ degree (Diamond, 2014). Hence, the LEU fuel would cause an increase in shim arm angle of approximately $(0.15 / 0.65) 0.23^{\circ}$, which is less than the normal expected uncertainty in shim arm position.

The suggested acceptance criterion for the shim arm critical position is that it should be within $1.0^{\circ}$ of the normally calculated ECP. It is assumed that the ECP would at that time include a correction for LEU fuel. For the first Phase-1 cycle the correction is $+0.23^{\circ}$ as calculated above. For the final eight transition cores (four FEs loaded each cycle) an example of the corresponding 
changes is shown in (Hanson, 2013a) taking into account an assumed, non-standard, cycle length for the first cycle.

\subsection{Regulating Rod and Shim Arm Worth}

The regulating rod and shim arm worth measurements are taken every year to assure that the excess reactivity, shutdown margin, and maximum reactivity insertion rate, are within Tech Spec limits. The procedures are given in (NIST, 2014).

The regulating rod worth is measured in a standard way by moving the rod from a critical state, measuring the resulting period and then using the inhour equation to determine reactivity. This is done with the regulating rod fully inserted and at three other initial positions until the rod is completely withdrawn. Once these data are obtained, the calculated differential shim arm worth can be fit to the measured data.

The shim arm worth measurements are of two types. The first is a measurement of differential shim arm worth at the critical configuration at startup. Differential worth is calculated to be at a maximum near this critical position. The shim arms are moved together, putting the reactor on a period that is used with the inhour equation to determine the worth/degree for that particular movement. This measurement is done with the regulating rod fully inserted and fully withdrawn. The higher of the two measurements, when multiplied by the measured speed of shim arm withdrawal, provides the maximum reactivity insertion rate for the shim arms. The acceptance criterion is the Tech Spec limit of $5 \times 10^{-4} \Delta \rho / \mathrm{s}$.

The second type of measurement is the differential worth of individual shim arms. This is done starting with one shim arm completely inserted, the regulating rod withdrawn and the remaining shim arms at a critical position. The inserted shim arm is withdrawn while maintaining criticality with the regulating rod until the regulating rod is fully inserted. The differential worth of the shim arm during that movement is the worth of the regulating rod measured as described above. The regulating rod is then withdrawn, with the three shim arms moving to compensate, so that the reactor is again at criticality and another measurement of a single shim arm movement can be made as before. This measurement is repeated several times until the shim arm being measured is totally withdrawn. This is possible as the regulating rod is only worth $\sim 0.5 \% \Delta \rho$ whereas a single shim arm worth is an order of magnitude larger. The core will reach a condition at the end of the set of measurements for a single shim arm when that arm is withdrawn and the regulating rod is inserted and the remaining three shim arms are at a critical position. Before the next shim arm is measured, the regulating rod is withdrawn and the three shim arms are inserted. An acceptance criterion for this condition is that the reactor must be shutdown with the one shim arm withdrawn and the others inserted. The shutdown margin for this condition requires analysis of the test results as explained below.

The results of the above measurements are the differential and total worths of each shim arm and their sum, i.e., the total worth of all shim arms. To determine if the excess reactivity is within the Tech Spec limit, one notes the initial critical position with all shim arms banked together. The worth of the shim arms moving from this critical position to fully withdrawn is defined as 
the excess reactivity. The acceptance criterion for the maximum excess reactivity is the Tech Spec limit of $15 \% \Delta \rho$.

The shutdown margin is based on the highest worth shim arm being withdrawn along with the regulating rod. Starting again from the just-critical shim arm position, the differential worth measurements of the shim arms provide the data that can be used to obtain the shutdown margin. The acceptance criterion for the minimum shutdown margin is the Tech Spec limit of $0.757 \% \Delta \rho$.

\subsection{Other Tests}

There are several other measurements that would not be part of the startup test report but are relevant. At every startup there is an extensive radiological survey throughout the reactor building and beyond. Any anomalous reading under normal operation, and certainly with new LEU fuel, would trigger an investigation.

There are also measurements that provide additional validation of the calculations used for operational and safety support. Measurements of neutron flux can be based on foil irradiations such as those used in the past to make measurements in the RT-2 rabbit facility in order to facilitate its use for activation analysis (Lindstrom, 2008 and Şahin, 2014). This provides a local measurement as opposed to a global measurement such as reactivity and is important as the most significant change in the reactor due to the replacement of the HEU with LEU is a shift of the peak flux distribution from the outer core to the inner core. Also of interest is any change in the energy spectrum of the neutron flux, although this is expected to be small (Brown, 2013). These measurements are probably most useful when the core is completely converted or at least no sooner than when there is significant LEU loading. More than ten different foil materials have been used at the NBSR in the past and these can be used again to compare with the previous measurements in the HEU core. Other foils can be used if desirable and cadmium covered foils can be used to obtain the thermal-to-epithermal flux ratio. All measurements can be compared with the results of calculations.

Two reactivity coefficients that should be relatively easy to measure and will give additional assurance (relative to calculation) that the reactor has inherent negative feedback are the power coefficient and the isothermal temperature coefficient. The former is obtained by recording shim arm position (and hence reactivity) during a power ascension. The coefficient is obtained directly if coolant temperature remains constant or is obtained by subtracting out the effect of a coolant temperature coefficient if that temperature also changes. The coolant temperature coefficient measurement requires changing flow and/or heat exchanger conditions in order to increase inlet temperature and measuring shim arm position (and hence reactivity) to maintain constant power. Power would need to be low so that the result is truly an isothermal coefficient. 


\section{REFERENCES}

Brown, N.R., Hanson, A.L., and Diamond, D.J., "Local Burn-Up Effects in the NBSR Fuel Element," BNL-99145-2013-IR, Brookhaven National Laboratory, January 23, 2013.

Cuadra, A. and Cheng, L.-Y., "Statistical Hot Channel Analysis for the NBSR," BNL-1052882014-IR, Brookhaven National Laboratory, May 23, 2014.

Diamond, D.J., Baek, J.S., Hanson, A.L., Cheng, L.-Y., Brown, N.R., and Cuadra, A., "Conversion Preliminary Safety Analysis Report for the NIST Research Reactor," BNL-1072652015-IR, Brookhaven National Laboratory, December 30, 2014.

Eyers, B. and Williams, R., "Program for Estimated Critical Position,' Personal communication from NIST Center for Neutron Research, September 2015.

Hanson, A.L. and Diamond, D.J., "Planning the HEU to LEU Transition for the NBSR,'RERTR $2011-33^{\text {rd }}$ International Meeting on Reduced Enrichment for Research and Test Reactors, Santiago, Chile, October 23-27, 2011.

Hanson, A.L., Brown, N.R., and Diamond, D.J., "Analysis of Lead Acceptance Elements for the NBSR,” BNL Technical Report, Brookhaven National Laboratory, September 25, 2012.

Hanson, A.L. and Diamond, D.J., "Transition Core Properties During Conversion of the NBSR from HEU to LEU Fuel," BNL-102419-2013-IR, Brookhaven National Laboratory, November 13, 2013a.

Hanson, A.L., Brown, N.R., and Diamond, D.J., "Effect of Shim Arm Depletion in the NBSR," BNL-99764-2013-IR, Brookhaven National Laboratory, February 21, 2013b.

IAEA, "Research Reactor Core Conversion Guidebook," IAEA-TECDOC-643, International Atomic Energy Agency (IAEA), 1992.

Lindstrom, R.M. et al., "Neutron Irradiation in Activation Analysis: A New Rabbit for the NBSR," J Radioanal Nucl Chem, 278, p 665, 2008.

Marcum, W.R., "National Bureau of Standards Reactor Fuel Element Flow Test - Technical and Functional Requirements," OSU-HMFTF-996000-TECH-001, Oregon State University, Draft 2013.

NIST, "Technical Specifications for the NIST Test Reactor (NBSR)," Appendix A to License No. TR-5, National Institute of Standards and Technology (NIST), 2009.

NIST, "Safety Analysis Report (SAR) for License Renewal for the National Institute of Standards and Technology Reactor - NBSR; NBSR 14, Rev 4," National Institute of Standards and Technology (NIST), Gaithersburg, MD, 2010. 
NIST, "Technical Specifications Procedures 4.1.2; Core Excess Reactivity/Shutdown Margin Reactivity Worth of each Shim Arm and Reg Rod, Revision A," National Institute of Standards and Technology (NIST), January 31, 2014.

NIST, "NIST Test Reactor (NBSR) Procedure; Operating Instruction 1.1; Reactor Startup, Revision A," National Institute of Standards and Technology (NIST), 2015.

NRC, "Guidelines for Preparing and Reviewing Applications for the Licensing of Non-Power Reactors; Format and Content," NUREG/CR-1537, Part 1, and "Guidelines for Preparing and Reviewing Applications for the Licensing of Non-Power Reactors; Standard Review Plan and Acceptance Criteria," NUREG/CR-1537, Part 2, U.S. Nuclear Regulatory Commission, February, 1996.

Şahin, D., Radulović, V., Lindstrom, R.M., and Trkov, A., "Reevaluation of Neutron Flux Characterization Parameters for NIST RT-2 Facility, J Radioanal Nucl Chem, 300, p 499, 2014.

Woolstenhulme, N.E., "DDE-NBSR Status Report of Conceptual Design Activities, INL/EXT12-27079, Idaho National Laboratory, September 2012. 


\section{APPENDIX A LOADING PATTERNS FOR TRANSITION CORES}

The loading pattern or core layout for an equilibrium HEU or LEU core is given in Figure 1 in Section 2. During Phase-1 of the transition two LEU fuel elements are loaded (along with two HEU elements) and move through the core for eight cycles before more LEU is introduced (see Figure 2). Figure A-1 shows how this would occur in the west half of the core. The east half would follow similarly as the loading pattern is symmetric in each half-core. Column 1 in the figure arbitrarily labels the $15 \mathrm{FEs}$ in this half-core as $\mathrm{H} 1$ to $\mathrm{H} 15$ located in the grid location given in column 2 for the HEU equilibrium core (H-EQ). The burnup of any FE can be obtained by relating to Figure 1. The first cycle of Phase-1 transition adds LEU fuel element labeled L1 and HEU fuel element labeled H31 (H16-H30 are assumed to be in the east half-core.) and shows the discharge (DIS) of FEs labeled H8 and H15. All additional movements from cycle to cycle are given in the next eight columns which show the original fuel above the heavy horizontal line and the introduction of new fuel below that line. In the ninth cycle it is time to load another LEU element (L2) into the half-core and then the process repeats itself again. The LEU elements are outlined in yellow on the figure.

The loading pattern during the Phase-2 transition is shown in Figure A-2. Cycle 1 in this figure replaces the Cycle 9 shown in Figure A-1. Now there are four LEU fuel elements loaded in each cycle. This is shown as FEs labeled L3 and L5 in column 2. (FEs labeled F4 and F6 would be loaded in the east half-core.) Each cycle shows the change in loading pattern until Cycle 8 is reached at which point the core is loaded entirely with LEU fuel elements. The LEU elements are again outlined in yellow on the figure. The last column shows the FE burnup during the final transition cycle consistent with Figure 1. Hence, FE labeled L3, now in position F5 is an 8-8W element; that is, it is an 8-cycle element in its eighth cycle in the west half-core. 


\begin{tabular}{|c|c|c|c|c|c|c|c|c|c|c|}
\hline Cycle-> & H-EQ & 1 & 2 & 3 & 4 & 5 & 6 & 7 & 8 & 9 \\
\hline \multicolumn{11}{|l|}{ FE \# } \\
\hline H1 & D1 & D7 & $\mathrm{C} 2$ & B5 & F7 & C4 & F3 & F5 & DIS & \\
\hline $\mathrm{H} 2$ & D7 & $\mathrm{C} 2$ & B5 & F7 & C4 & F3 & F5 & DIS & & \\
\hline H3 & $\mathrm{C} 2$ & B5 & F7 & C4 & F3 & F5 & DIS & & & \\
\hline $\mathrm{H} 4$ & B5 & F7 & C4 & F3 & F5 & DIS & & & & \\
\hline H5 & F7 & C4 & F3 & F5 & DIS & & & & & \\
\hline H6 & C4 & F3 & F5 & DIS & & & & & & \\
\hline H7 & F3 & F5 & DIS & & & & & & & \\
\hline H8 & F5 & DIS & & & & & & & & \\
\hline H9 & A4 & $\mathrm{F} 1$ & B3 & C6 & E2 & E6 & E4 & DIS & & \\
\hline H10 & F1 & B3 & C6 & E2 & E6 & E4 & DIS & & & \\
\hline H11 & B3 & C6 & E2 & E6 & E4 & DIS & & & & \\
\hline H12 & C6 & E2 & E6 & E4 & DIS & & & & & \\
\hline H13 & E2 & E6 & E4 & DIS & & & & & & \\
\hline H14 & E6 & E4 & DIS & & & & & & & \\
\hline H15 & E4 & DIS & & & & & & & & \\
\hline $\mathbf{L 1}$ & & $\mathrm{D} 1$ & D7 & $\mathrm{C} 2$ & B5 & F7 & C4 & F3 & F5 & DIS \\
\hline H31 & & A4 & F1 & B3 & C6 & E2 & E6 & E4 & DIS & \\
\hline H32 & & & D1 & D7 & $\mathrm{C} 2$ & B5 & F7 & C4 & F3 & F5 \\
\hline H33 & & & A4 & $\mathrm{F} 1$ & B3 & C6 & E2 & E6 & E4 & DIS \\
\hline H34 & & & & D1 & D7 & $\mathrm{C} 2$ & B5 & F7 & C4 & F3 \\
\hline H35 & & & & A4 & F1 & B3 & C6 & E2 & E6 & E4 \\
\hline H36 & & & & & D1 & D7 & $\mathrm{C} 2$ & B5 & F7 & C4 \\
\hline H37 & & & & & A4 & F1 & B3 & C6 & E2 & E6 \\
\hline H38 & & & & & & D1 & D7 & $\mathrm{C} 2$ & B5 & F7 \\
\hline H39 & & & & & & A4 & F1 & B3 & C6 & E2 \\
\hline H40 & & & & & & & D1 & D7 & $\mathrm{C} 2$ & B5 \\
\hline H41 & & & & & & & A4 & F1 & B3 & C6 \\
\hline H42 & & & & & & & & D1 & D7 & $\mathrm{C} 2$ \\
\hline $\mathrm{H} 43$ & & & & & & & & A4 & $\mathrm{F} 1$ & B3 \\
\hline $\mathrm{H} 44$ & & & & & & & & & D1 & D7 \\
\hline $\mathrm{H} 45$ & & & & & & & & & A4 & F1 \\
\hline L3 & & & & & & & & & & D1 \\
\hline H61 & & & & & & & & & & A4 \\
\hline
\end{tabular}

Figure A-1. Fuel Loading Pattern During Phase-1 Transition 


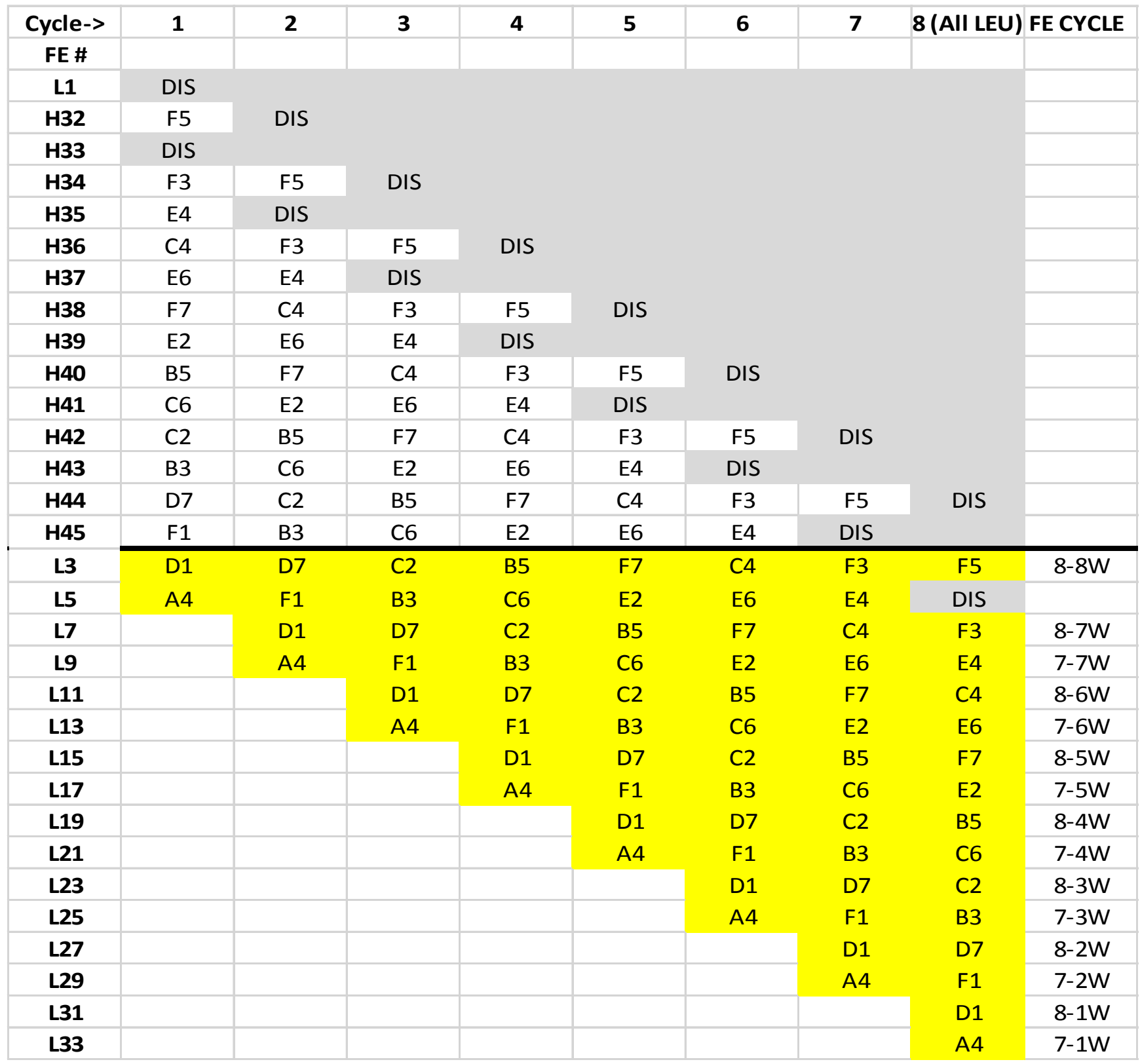

Figure A-2. Fuel Loading Pattern During Phase-2 Transition 